\title{
COLD BENDING CHARACTERISTICS OF MAG PULSE WELDING OF API 5LX65 THERMO MECHANICAL TREATED STEEL
}

\author{
Dinu SIMIONESCU, Ion MITELEA, Mircea BURCĂ, Dragoş UŢU \\ „Politehnica“ University of Timisoara, Timisoara, Romania, EU \\ rector@upt.ro, dinusim@yahoo.ca, ion.mitelea@upt.ro, mburcă55@yahoo.com, dragos.utu@upt.ro
}

https://doi.org/10.37904/metal.2019.704

\begin{abstract}
Thermo mechanical treated steel API 5LX65 has high mechanical characteristics and is intended for the welding of main pipelines for the oil and natural gas transportation.

The pipes made of this steel have a diameter of 42 " $(1066.8 \mathrm{~mm})$ and a wall thickness of $31.75 \mathrm{~mm}$. They were welded by narrow gap MAG welding selecting a filler metal for the root layer and another filler metal for the filling layers. Testing of the plastic deformation behavior of the welded joints was done by cold bending tests on both specimens in which the longitudinal axis of the welded joint is perpendicular to the axis of the support rollers and parallel to the direction of application of the force as well as on the notched specimens. The results obtained were corroborated with macro - and micro fractographic investigations
\end{abstract}

Keywords: Thermomechanical treatment steel, welding, cold bending

\section{INTRODUCTION}

The oil and natural gas transport is based on the development of new underground or submarine pipeline networks. The basic structural element of a pipeline is the steel pipe. These pipes, which assembled lead to the construction of a pipeline system, must meet certain basic requirements:

to be made of steels with high mechanical characteristics; to exhibit good resistance to loss of stability (flatting - when used in submarine pipelines); to ensure environmental protection, which means high operational safety and high reliability; manufacturing costs to be reduced and their installation to be done easily.

In addition, the materials that compete to the pipeline must have high corrosion stability and good metallurgical and technological welding behavior [1], [2]. The steel selection activity for such applications is based on a complex of metallurgical factors (carbon content reduction, microalloying, non-metallic inclusions control) and technological (controlled lamination, thermomechanical treatments) that favor the improvement of the mechanical resistance characteristics without a sensitive decrease in the characteristics of ductility and tenacity [3], [4].

Worldwide, pipeline construction is governed by a series of standards of which a wide recognition have:

API Specification 5L. Specification for Line Pipe. (API, 2018) - Specification of the American Petroleum Institute; EN 10208. Steel pipes for pipe lines for combustible fluids. Technical delivery conditions (EN 102082009) -European Standard; Det Norske Veritas - Germanischer Lloyd. DNVGL-ST-F101 Submarine pipeline system (2017) - Det Norske Veritas Germanisher Lloyd Norvegian Standard.

This paper aims to assess the plastic deformation capacity of the narrow gap MAG welded joints with multiple layers, a single pass per layer, to the main pipelines having a diameter of 42 " $(1066.8 \mathrm{~mm})$ and a wall thickness of $31.75 \mathrm{~mm}$ of API $5 \mathrm{~L}$ X65M steel, thermo mechanical treated.

\section{MATERIALS, EXPERIMENTAL PROCEDURE}

Table 1 shows the chemical composition of the base metal, and in Tables 2 and $\mathbf{3}$ the chemical composition of the filler metals. 
Table 1 Chemical composition of base material: API 5L X65M (wt.\%)

\begin{tabular}{|c|c|c|c|c|c|c|c|c|c|c|c|c|}
\hline X65M & $\mathrm{C}$ & $\mathrm{Si}$ & $\mathrm{P}$ & $\mathrm{S}$ & $\mathrm{Ti}$ & $\mathrm{Mn} \%$ & $\mathrm{Ni} \%$ & $\mathrm{Cr} \%$ & $\mathrm{Al}$ & $\mathrm{Mo}$ & $\mathrm{V} \%$ & $\mathrm{Nb} \%$ \\
\hline Actual values & 0.043 & 0.32 & 0.007 & 0.0009 & 0.013 & 1.53 & 0.018 & 0.19 & 0.038 & 0.008 & 0.004 & 0.044 \\
\hline
\end{tabular}

Table 2 Chemical composition of welding consumable for root pass, ER70S-G (wt.\%)

\begin{tabular}{|c|c|c|c|c|c|c|c|c|c|c|c|}
\hline ER70S-G & $\mathrm{C}$ & $\mathrm{Si}$ & $\mathrm{Mn}$ & $\mathrm{P}$ & $\mathrm{S}$ & $\mathrm{Cr}$ & $\mathrm{Mo}$ & $\mathrm{Ni}$ & $\mathrm{Cu} \%$ & $\mathrm{~V} \%$ & $\mathrm{Ti}$ \\
\hline $\begin{array}{c}\text { Actual } \\
\text { values }\end{array}$ & 0.07 & 0.74 & 1.57 & 0.013 & 0.008 & 0.04 & 0.01 & 0.04 & 0.11 & 0.01 & 0.05 \\
\hline
\end{tabular}

Table 3 Chemical composition of the welding consumable for fill layers, ER70S-6 (wt.\%)

\begin{tabular}{|c|c|c|c|c|c|c|c|c|c|c|}
\hline ER70S-6 & $\mathrm{C}$ & $\mathrm{Si}$ & $\mathrm{Mn}$ & $\mathrm{P}$ & $\mathrm{S}$ & $\mathrm{Cr}$ & $\mathrm{Mo}$ & $\mathrm{Ni}$ & $\mathrm{Cu} \%$ & $\mathrm{~V} \%$ \\
\hline Actual values & 0.07 & 0.95 & 1.69 & 0.011 & 0.010 & 0.03 & 0.01 & $0.05 \%$ & 0.10 & 0.01 \\
\hline
\end{tabular}

Narrow gap welded joints were made by MAG spray arc for the root \& hot passes and pulse current for the fill layers. The welding equipment from CRC Evans is composed by an internal welding machine IWM for the root pass and two external ones, P625, each one with two welding torches for the filling layers, where the pipe is fix and the welding equipment make a downward vertical orbital movement around the pipe.

The bending tests were carried out by means of a device provided with a mandrel that stress the specimen (Figure 1) and which is installed on a hydraulic press (Figure 2).

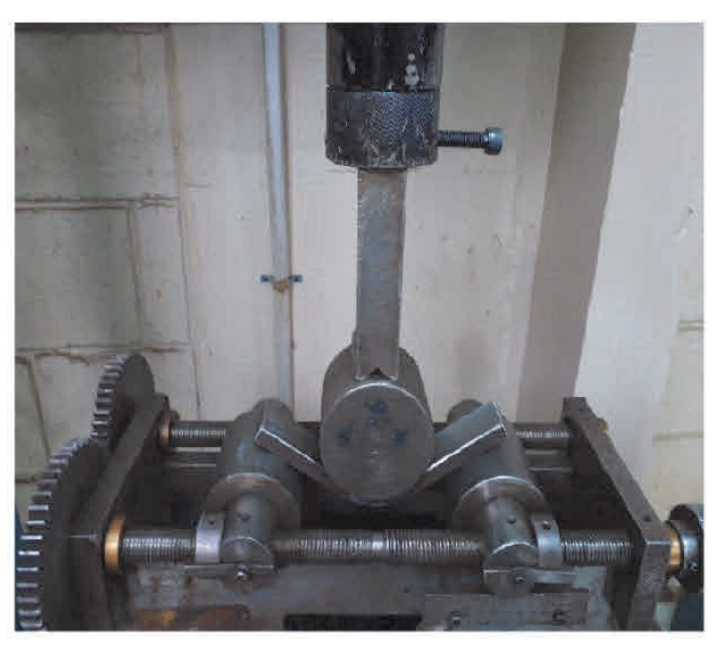

Figure 1 Bending device picture

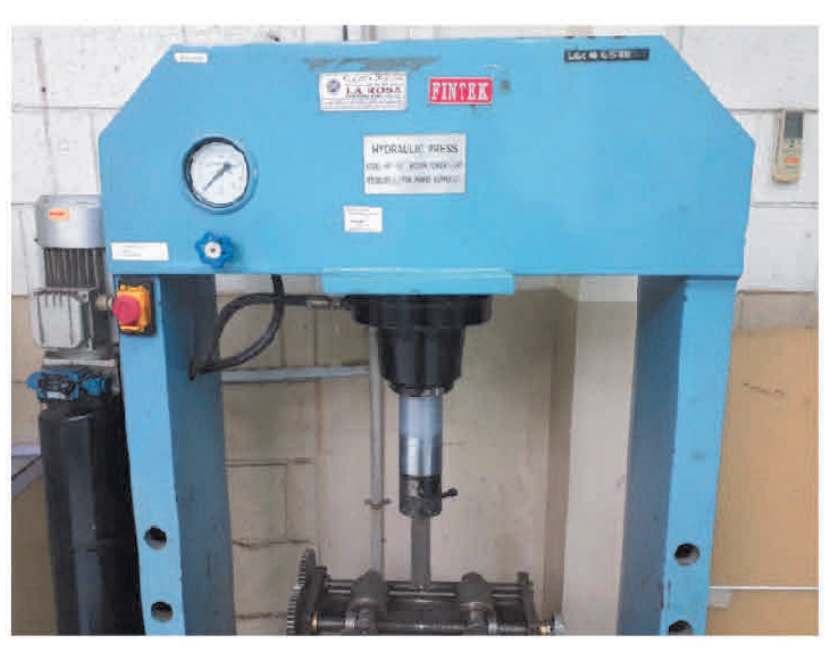

Figure 2 Hydraulic press for cold bending

Some of the specimens were subjected to a lateral bending test in which the longitudinal axis of the weld seam is perpendicular to the axis of the support rollers and parallel to the direction of the applied force.

Further tests were conducted on specimens with the section reduced in the welded joint axis by the execution of a notch

\section{EXPERIMENTAL RESULTS}

\subsection{Side bend test}

This test method is suitable for multilayer welded joints examination, because it makes possible to analyse the global behavior of weld section. 
The location of the side bend specimens is shown in Figure 3 and their shape and dimensions according to API standard 1104, 2013, are shown in Figure 4.

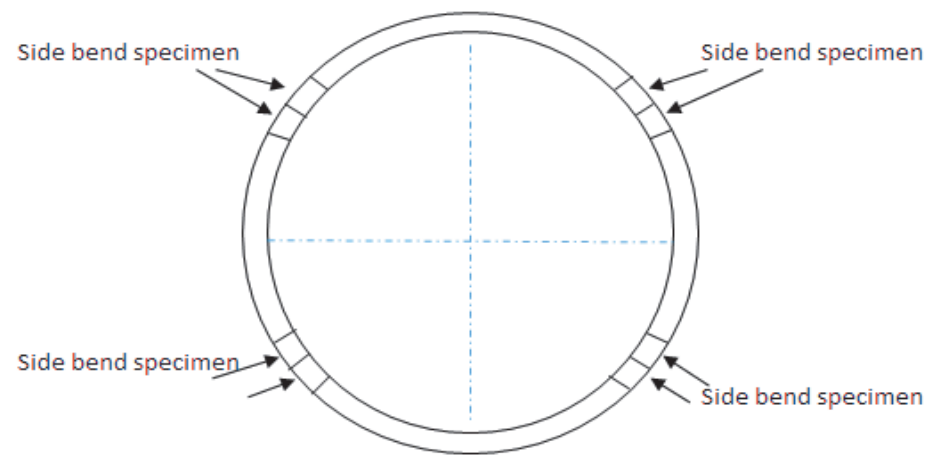

Figure 3 Location of side bend test specimens

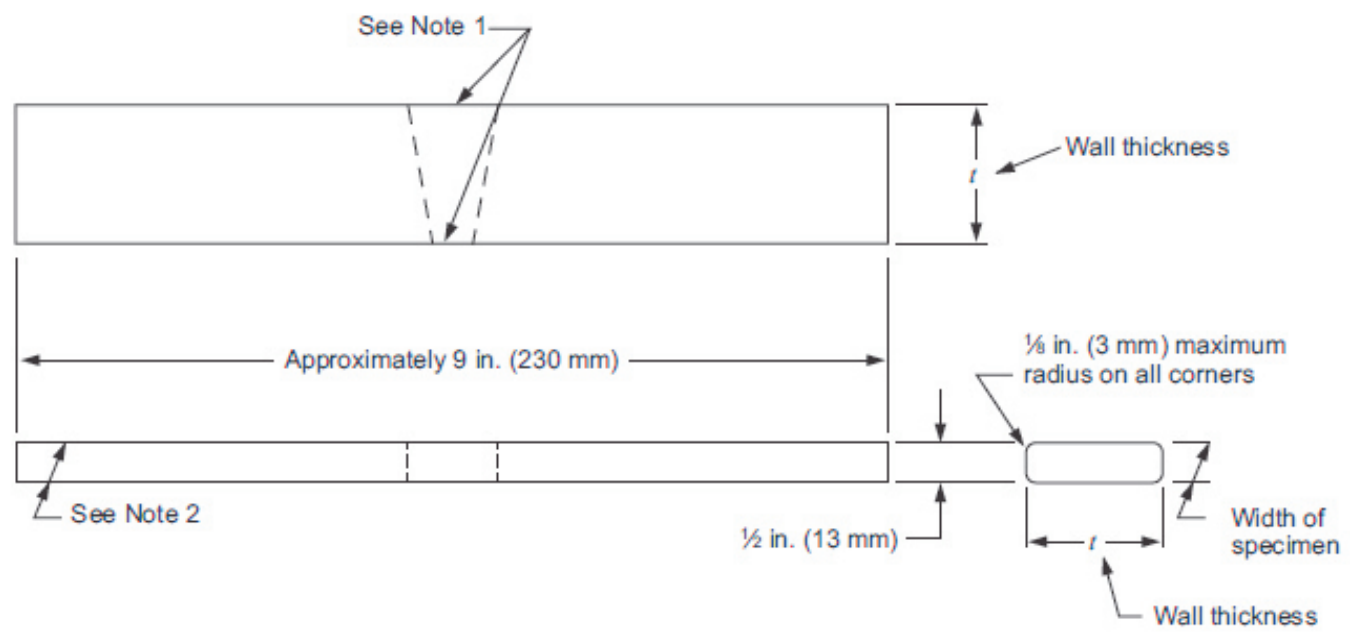

NOTE 1 The weld reinforcement is removed from both faces flush with the surface of the specimen.

NOTE 2 Specimens may be machine cut to a width of $1 / 2$ in. $(13 \mathrm{~mm})$, or they may be oxygen cut to a width of approximately $3 / \mathrm{s}$ in. (19 mm) and then machined or ground smooth to a width of $1 / 2$ in. $(13 \mathrm{~mm})$. Cut surfaces are smooth and parallel.

Figure 4 Geometry of side bend test specimens

Each specimen was placed on the support rollers of the device and subjected to the bending stress using the mandrel/plunger until required bend angle of the specimen was obtained. The welded joint was placed and maintained in the area of maximum deformation. The cover and root bead reinforcements were removed flush with the surfaces of the specimen. Appearance of sample before test and image of side bend test specimen show Figure 5 and 6.

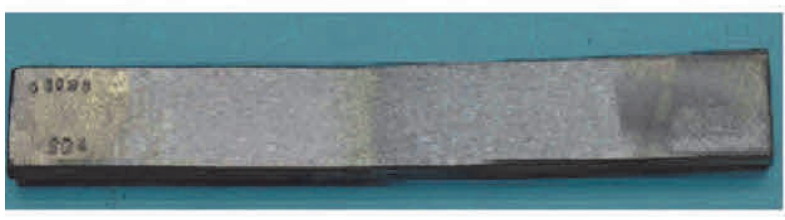

Figure 5 The appearance of the specimen before the test (API 5L X65M, 42 "(1066.8 mm) x $31.75 \mathrm{~mm}$ )

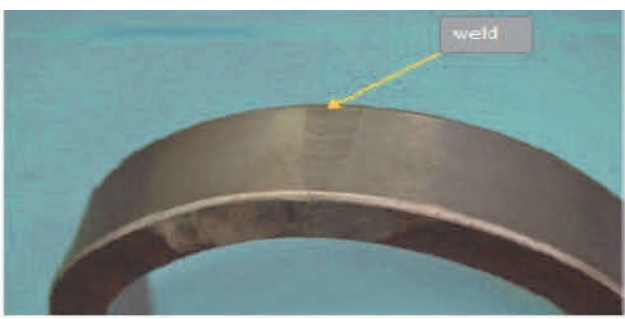

Figure 6 The image of side bend test specimen 
The results of the side bend tests are shown in Table 4 remarking that until $180^{\circ}$ angle no cracks have been observed.

Table 4 Test conditions and results

\begin{tabular}{|c|c|c|c|}
\hline Specimen ID & Mandrel diameter $(\mathrm{mm})$ & Bend angle $\left.{ }^{\circ}\right)$ & Results \\
\hline SB1 & 90 & 180 & Acceptable \\
\hline SB2 & 90 & 180 & Acceptable \\
\hline SB3 & 90 & 180 & Acceptable \\
\hline SB4 & 90 & 180 & Acceptable \\
\hline SB5 & 90 & 180 & Acceptable \\
\hline SB6 & 90 & 180 & Acceptable \\
\hline SB7 & 90 & 180 & Acceptable \\
\hline SB8 & 90 & 180 & Acceptable \\
\hline
\end{tabular}

\subsection{Bending test of specimens with notch}

For such tests the specimens were used with reduced section in the welded joint axis by performing a notch to cause complete break. The intended purpose on the one hand is to assess the fracture behavior and on the other hand, identifying, location, establishing the cause and the size of the welding defects. Figure 7 shows the location of the nick break test specimens and in Figure 8 according to API standard 1104, 2013 the dimensions of the specimens with bilateral notch along the longitudinal axis of the weld seam.

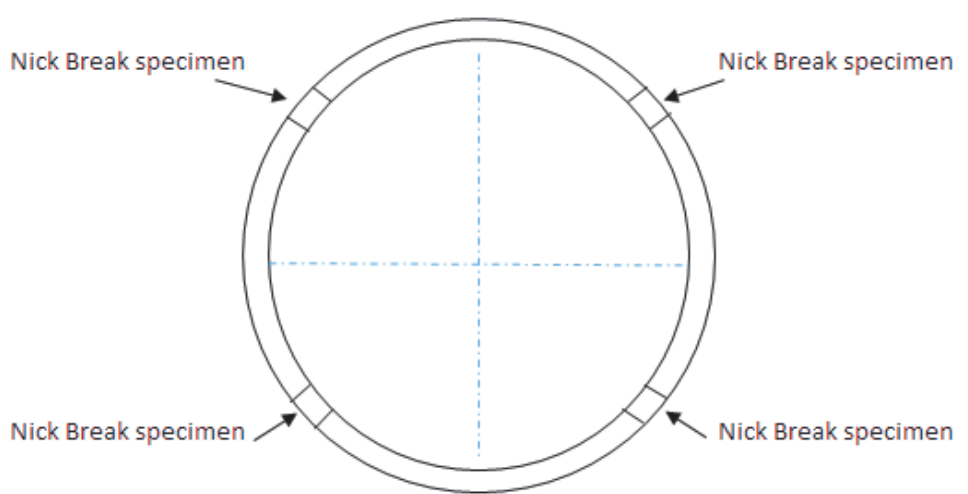

Figure 7 Location of nick break test specimens

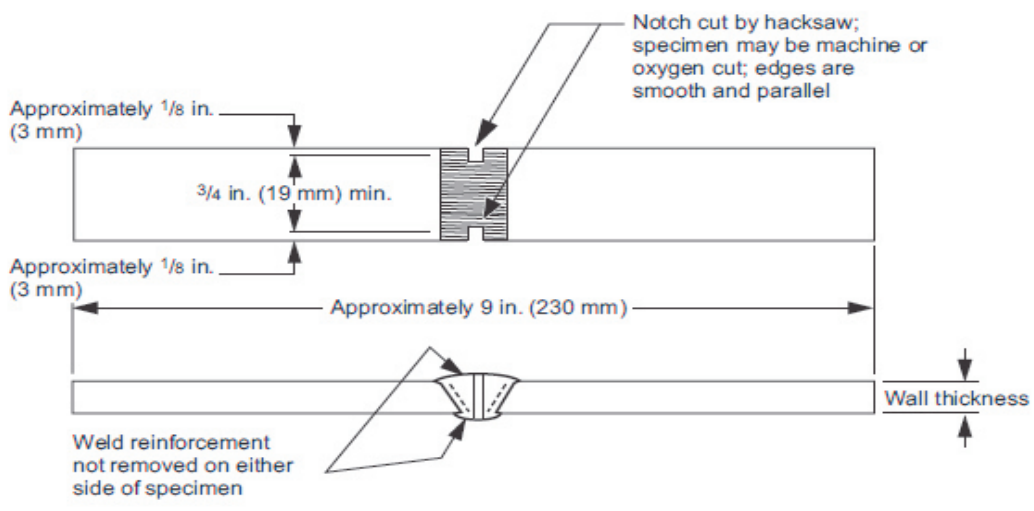

Figure 8 The shape and dimensions of the specimens with notch 
The macroscopic images of the specimens with notch before and after the cold bending test are illustrated in Figure 9a and Figure 9b.

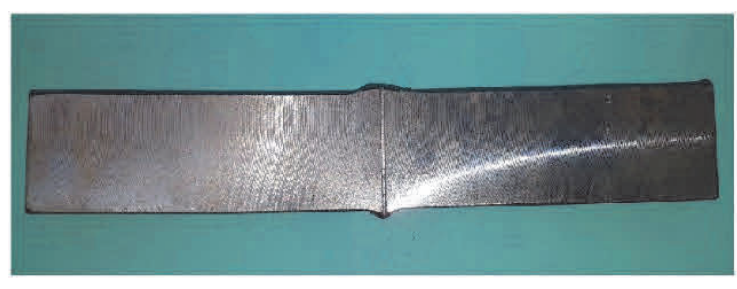

-a-

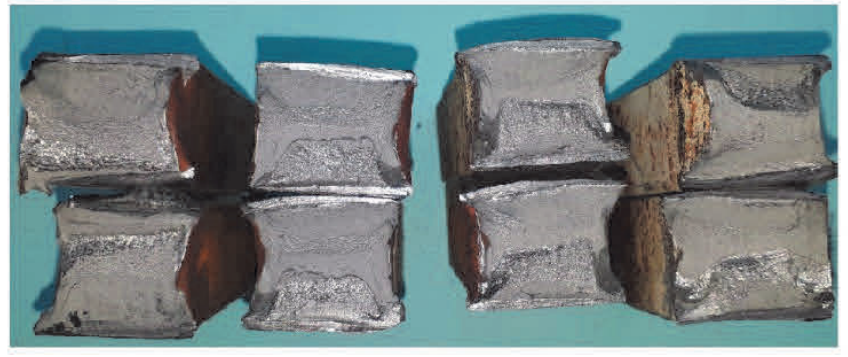

$-b-$

Figure 9 Macrographic specimens with notch, API 5L X65M, 42 "(1066.8 mm) x $31.75 \mathrm{~mm}$ : a - before the test; $\mathrm{b}$ - after testing

It is noted that specimens rupture is preceded by significant plastic deformation and that no metallic continuity defects have been observed.

\subsection{Microfractographic examinations}



-a-

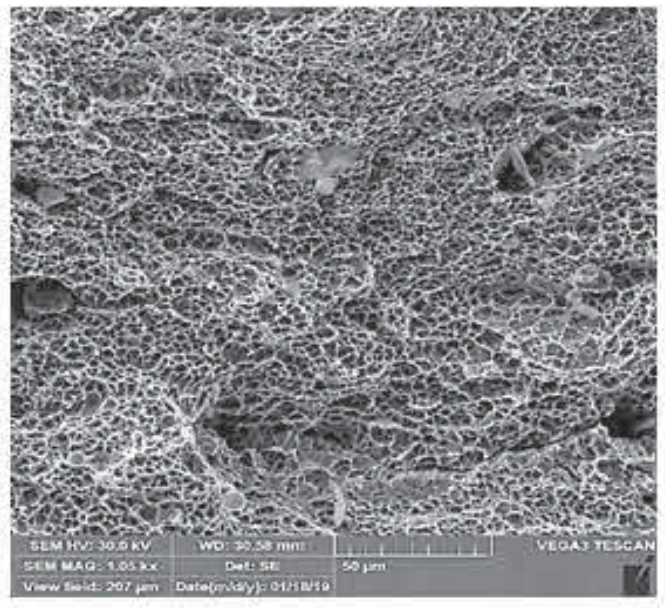

-C-

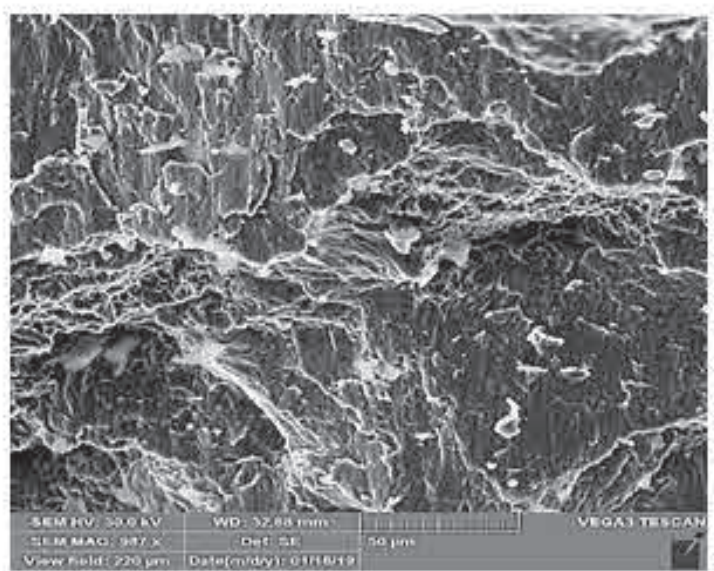

$-b-$

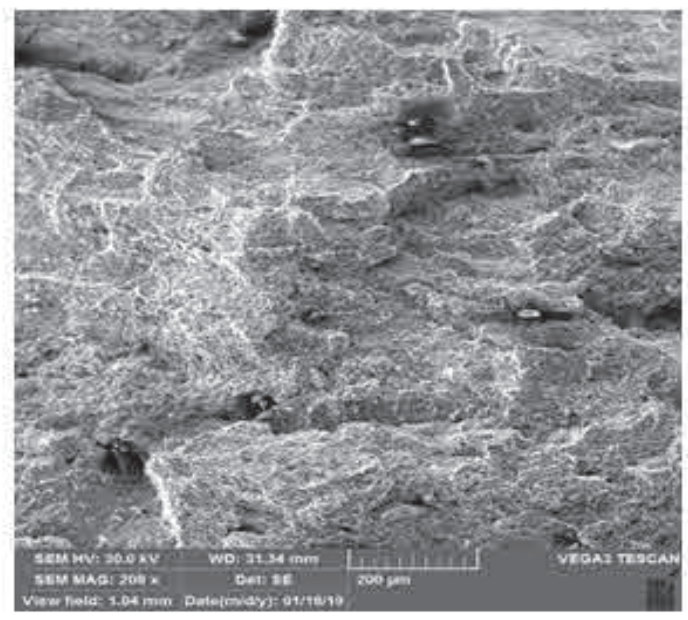

$-d-$

Figure 10 Microfractography of fracture surfaces: a, b - welded root area; c, d - last filling layer 
Figures 10a to $10 \mathrm{~d}$ illustrate the micro fractographic aspects of the fracture areas from the welded root area, respectively from the last filling layer. The present cavities characterize the ductile fracture of the material. They have a concave structure resulting from the fracture of several vacancies that are initiated and increased in the plastic deformation process. Since the fracture plane is perpendicular to the axis of stress, the formed cavities are predominantly equiaxed. Along with large variations in cavity size, another feature of fracture surfaces is ductile cleavage.

\section{CONCLUSIONS}

Narrow gap MAG pulse welding with multiple layers made of X65M thermos mechanically treated steel have a high capacity of plastic deformation, proven by the absence of cracks in the welding seam until reaching the $180^{\circ}$ bending angle.

The fracture surface of the notched specimens has a matte-fibrous appearance and its character is ductile, characterized by a low speed of the crack displacement, respectively, by large amounts of energy absorbed for its propagation.

\section{REFERENCES}

[1] KIM, H. K., MOON, J. I., Kim W. K., PARK, G. B. and LEE, S. K. Influence of carbon equivalent value on the weld bead bending properties of high-strength low-alloy steel plates. Journal Materials Science and Technology. 2017. vol. 33, no 4, pp. 321 - 329.

[2] JEONG, S., PARK, G., KIM B., MOON, J., PARK, J. and LEE, C. Precipitation behavior and its effect on mechanical properties in weld heat-affected zone in age hardened FeMnAIC lightweight steels. Journal Materials Science and Engineering. 2019. vol. 742A, pp. 621 - 68.

[3] SIMIONESCU, D., MITELEA, I., BURCA, M. Opportunities of narrow gap MAG welding of API 5L X65M steel pipeline. In METAL 2017: 26th International Conference on metallurgy and materials. Ostrava: TANGER, 2017, pp: 699-704.

[4] SIMIONESCU, D., MITELEA, I., BURCA, M. and UTU, I.D. Mechanical behaivor of narrow gap MAG welding of API 5L X65M steel pipeline. IOP Conference Series: Materials Science and Engineering. 2018, vol. 416, pp.1-8. 